\title{
Top-Selling Herbal Supplements
}

\author{
Kathryn L. Grant
}

\begin{abstract}
OBJECTIVE: To familiarize pharmacists with the pharmacology, indications, doses, standardization, adverse effects, and interactions of eight of the best-selling herbal supplements-echinacea, garlic, ginkgo, ginseng, kava, saw palmetto, St. John's wort, and valerian - to enable them to better help patients wisely choose herbal supplements, monitor herbal supplement use, and counsel patients regarding potential problems.

Specific learning objectives include:
\end{abstract}

$\Delta$ Define DSHEA and list the implications of that act for pharmacists and patients.

$\Delta$ Given an herbal supplement: 1) determine an acceptable indication and dose for that indication; 2) list the common or serious side effects induced by that supplement; and 3) provide information applicable for patient counseling.

\section{DATA SOURCES: Literature references.}

CONCLUSION: Given the growth in interest and huge sales volume of herbal supplements, pharmacists must become knowledgeable about these products to help patients sort factual from fraudulent information. Although the Dietary Supplement Health and Education Act of 1994 allows the sales of these products as dietary supplements, they can be sold without evidence of their safety or efficacy. Good manufacturing procedures are being written, but manufacturers as yet have no regulatory control over the quality of the products being produced.

KEYWORDS: Efficacy, Commission E, Echinacea, Garlic, Ginkgo, Ginseng, Kava, Saw palmetto, St. John's wort, Valerian

J Managed Care Pharm 1999: 357-66

\section{$\Delta$ \\ AUTHOR}

KATHRYN L. GRANT, PHARM.D., EA.S.H.P., is Assistant Professor, College of Pharmacy, The University of Arizona, Tucson, $A Z$.

ACKNOWLEDGEMENT: The author wishes to thank Kevin Keyes, pharmacy student, for help in preparing the kava and valerian monographs.

Copyright@ 1999 Academy of Managed Care Pharmacy, Inc. All rights reserved.

的.

CE CREDIT: This is article number 233-000-99-004-HOI in AMCP's continuing education program. It affords 1 hour (.1 CEU) of credit.

Learning objectives and test questions follow on page 369.
I nterest in herbal supplements continues to grow. ${ }^{1}$ In a. 1990 survey, only $2.5 \%$ of respondents had used an herbal remedy in the previous year; by 1997 this figure had increased to $12.1 \%$. Mass marketing data from 1997-98 confirm this trend, estimating the sale of herbal supplements at $\$ 663.4$ million, not including sales of herbal supplements from natural food stores. ${ }^{2}$ Accordingly, pharmacists must be aware of patients' use of, interest in, and vulnerability regarding herbal products.

Much of the literature on herbal supplements has been published in German, French, Chinese, and Japanese publications and is not readily accessible to the practicing pharmacist in this country. Ignoring this research, however, is not in the best interest of patient care. Furthermore, pharmacists and physicians who assume that all herbal supplements are "voodoo" medicine have only driven patients away from seeking professional advice about these products from conventional health care providers. Eisenberg's ${ }^{1}$ surveys determined that $39.8 \%$ of patients told their primary care provider about their use of alternative medicine in 1990 compared to $38.5 \%$ in 1997 , even as the numbers of patients using such supplements greatly increased.

Partnering with the patient to select the best herbal products will help avoid problems with dosing, adverse effects, and interactions, and also will gain the patient's trust and cooperation, allowing the pharmacist to truly be responsible for the patient's drug therapy. According to Hepler and Angaran, ${ }^{3}$ the "nature of caring" is an integral part of pharmaceutical care and includes decision making that takes into account not only scientific theory and knowledge, but also understanding of the patient's preferences or basic values as 
Top-Selling Herbal Supplements

Table 1. Sales Data and Major Indications of Selected Herbal Supplements

\begin{tabular}{l|l|c|l}
\hline Common Name & Plant Binomial & Mass-marketing Retail Sales Data (\$) & Major Indication(s) \\
\hline Ginkgo & ginkgo biloba & 138 million & $\begin{array}{c}\text { Alzheimer's disease, memory loss, peripheral } \\
\text { arterial occlusive disease, tinnitus, vertigo }\end{array}$ \\
\hline St. John's wort & hypericum perforatum & 121 million & depression \\
\hline Ginseng & panex ginseng & 98 million* & general tonic for fatigue and disability \\
\hline Garlic & allium sativum & 84 million & hypercholesterolemia \\
\hline Echinacea & echinacea purpurea & 33 million** & upper respiratory tract infections \\
\hline Saw palmetto & serenoa repens & 27 million & benign prostatic hypertrophy \\
\hline Kava & piper methysticum & 8 million & anxiety \\
\hline Valerian & valeriana officinalis & 8 million & insomnia \\
\hline
\end{tabular}

*This figure may include other ginseng species as well (e.g. p. quinquefolium).

** This sales figure may include other echinacea species as well (e.g. e. angustifolia, e. pallida).

Source: The booming U.S. botanical market: a new overview. HerbalGram 1998.

well as commitment to the interests of the patient. Astin's ${ }^{4}$ recently conducted survey concluded that patients choose alternative medicine primarily because these health care alternatives are more congruent with their own "values, beliefs, and philosophical orientations toward health and life."

The Dietary Supplement Health and Education Act of 1994 allowed the sales of herbal products as substances used orally to supplement the diet. ${ }^{5}$ Although provisions for eventually establishing good manufacturing processes for these products were written into the act, no regulatory body currently has the authority to determine that these products are procured, stored, processed, or manufactured properly. Since these products are plants rather than single-agent synthetic chemicals, their complexity is far greater than that of conventional drugs. Helping patients choose the appropriate herbal remedy can be much more complex than selecting generic equivalents to known pharmaceuticals. The potency of the plant can be affected by such factors as where and under what conditions the plant was grown, and when the plants are harvested. How or if the final product is standardized also affects whether or not a product will show consistent quality from lot to lot. Thus, even with herbal supplements that have been well.studied, pharmacists can encounter difficulty in determining which products manufactured by an unregulated industry are safe and effective. These circumstances raise justifiable concerns regarding public safety.

The only published standards for efficacy, safety, and acceptable extracts are the monographs prepared by Commission E, established by the Second Medicines Act of Germany in $1976 .{ }^{\circ}$ Commission E required manufacturers to provide proof of pharmaceutical quality, but the commission itself prepared monographs using bibliographic data to provide safety and efficacy evaluations. These monographs provide the acceptable labeling for botanicals in wide commercial use in Germany prior to 1978. Where appropriate, Commission E-accepted labeling, standardizations, and doses have been added to the monographs presented below. Patients should be counseled to purchase products meeting these standardization and dosing guidelines.

The following brief monographs on the top-selling herbal supplements are provided in the interests of promoting awareness of the evidence supporting the use of herbal supplements. See Table 1 for sales data and major indications.

\section{GINKGO}

Ginkgo leaves are from the $G$. biloba tree, which belongs to a genus more than 200 million years old. ${ }^{7}$ Acetone-water extracts of the dried ginkgo leaves contain flavonoids (e.g. ginkgoflavoneglycosides), which are antioxidants. ${ }^{8}$ Extracts also contain terpene lactones (e.g. ginkgolides and bilobalides), which have shown platelet-activating factor inhibition. ${ }^{9}$ Pharmacologically, standardized extracts of ginkgo leaves induce vasodilation, increasing the blood flow in arteries and capillaries both centrally and peripherally. ${ }^{7.8}$

Ginkgo has been most widely studied as the extract EGb 761 standardized to $24 \%$ ginkgoflavoneglycosides and $6 \%$ terpene lactones ( $3.1 \%$ ginkgolides A, B, and C, $2.9 \%$ bilobalides) ${ }^{6,10}$ In Germany, the trade names for this specific extract include TeboninÆ and Tanakan/Æ. Another extract, Ll 1370 (Kaveri/A) is standardized similarly but has $25 \%$ ginkgoflavoneglycosides. Ginkgolic acid has been associated with allergies, so extracts should also be standardized to contain less than 5ppm ginkgolic acid." 
Table 2 lists the pharmacokinetic data on the ginkgoflavoneglycosides, ginkgolides (A and B), and bilobalide. ${ }^{8}$ Other constituents might alter the overall pharmacokinetics of ginkgo.

According to Commission E, accepted labeling for ginkgo includes its indication for the symptomatic treatment of disturbed performance in patients with organic brain syndrome and for improvement in pain-free walking distance in patients with peripheral arterial occlusive disease as well as treatment of vertigo and tinnitus. ${ }^{6}$ Two clinical trials have studied the efficacy of ginkgo biloba in the treatment of Alzheimer's disease or multiinfarct dementia. ${ }^{10.12}$ One study enrolled more than 30 patients with Alzheimer's disease or multiinfarct dementia. ${ }^{10}$ Patients were randomized to the standardized extract EGb 761 or placebo. The primary assessment tool used was the

Alzheimer's disease assessment scale-cognitive subscale. At the end of 52 weeks, patients on EGb 761 showed slowing of disease progression compared to placebo, similar to results found for acetylcholinesterase inhibitors. The other study enrolled more than 200 patients on either EGb 761 or placebo and used three different assessment tools. ${ }^{12}$ The response rate was defined as improved scores on at least two of the three assessment tools. With these response criteria, 15/79 (19\%) responded to ginkgo and $7 / 77(9 \%)$ responded to placebo $(\mathrm{p}<0.005)$. The only placebo-controlled randomized, double-blind study of ginkgo for the treatment of tinnitus was published in the mid1980s. ${ }^{13}$ The English abstract of this French study provides only that 103 patients were enrolled for a 13-month trial and that ginkgo was more effective than placebo. Another article, also in French, appears to document the efficacy of ginkgo for the treatment of vertigo in a multicenter, randomized, doubleblind, placebo-controlled study. ${ }^{14}$ According to an English abstract of this article, 70 patients were enrolled and treated for three months. Of those patients administered ginkgo, $47 \%$ were symptom free compared to $18 \%$ of patients given placebo.

Another indication promoted for ginkgo is memory loss improvement, but this indication requires further study in order to make a clinical recommendation on its usefulness. ${ }^{15}$ While ginkgo has been promoted for prevention of Alzheimer's disease, this indication has not been studied at all..$^{16}$

Side effects are primarily related to gastrointestinal upsets, although higher doses ( $150 \mathrm{mg}$ daily) have been associated with headache (about $3 \%$ ), burning eyes $(<0.01 \%)$ and breathless- ness $(<0.01 \%) .{ }^{8}$ The German government has set limits on ginkgolic acid to $<5 \mathrm{ppm}$ because this acid is an alkylphenol of the urushiol type (related to poison ivy) and could be associated with allergic reactions." Ginkgolic acids are present in greater quantities in the seeds as opposed to the leaves, but some suggest that teas made from the leaves not be used because of the potential for allergic reactions. Drug interactions have not been reported, but caution must be exercised if patients are already on medications inhibiting platelet aggregation such as aspirin or dietary supplements such as fresh garlic. ${ }^{17}$

The dose of the accepted standardized extract (e.g., EGb 761) as published in the Commission E monographs is $40 \mathrm{mg}$ three times daily orally. ${ }^{6}$ Doses in clinical trials have ranged from $60 \mathrm{mg}$ to $320 \mathrm{mg}$ daily. The higher dose was used short term for coronary bypass disease or in single doses to study ginkgo's effect on memory performance.

Ginkgo appears to be comparable in efficacy to, but less toxic than, acetylcholinesterase inhibitors for the treatment of Alzheimer's disease. Trials of ginkgo in patients with Alzheimer's disease appear to be warranted if, for example, donepezil has not produced the desired outcomes or has induced unacceptable toxicities. Given that no effective treatment for tinnitus or vertigo exists and given ginkgo's low toxicity, trials of ginkgo for the treatment of these ailments may be warranted. More research is needed to document ginkgo's efficacy in the other promoted indications.

\section{ST. JOHN'S WORT}

St. John's wort is a flowering perennial grown originally in Europe but now found both cultivated and as a weed in the United States and Canada. ${ }^{18}$ St. John's wort has an extensive history of oral use in Europe as a diuretic and antidepressant as well as in the treatment of gastritis and insomnia. The primary classes of constituents are the naphthodianthrones (hypericin and pseudohypericin), flavonoids (e.g., quercetin), phloroglucinols (e.g., hyperforin), essential oils, and xanthones..$^{18}$ As with many other herbal supplements, no one constituent is entirely responsible for clinical activity. Most of the research to date has been conducted on hypericin with products standardized to $0.3 \%$ hypericin. Hyperforin also may contribute to the efficacy of St. John's wort. ${ }^{19}$

Table 2. Pharmacokinetics on Selected Ginkgo Constituents

\begin{tabular}{l|c|c|c}
\hline Pharmacokinetic parameter & Ginkgoflavoneglycosides & Ginkgolides (A or B) & Bilobalide \\
\hline Oral bioavailability (\%) & $>60$ & $>98(\mathrm{~A})>80(\mathrm{~B})$ & 70 \\
\hline Time to peak concentration (hrs) & $1.5-3$ & $1-2$ & $1-2$ \\
\hline Volume of distribution (liters) & No data & $40-60(\mathrm{~A}) 60-100(\mathrm{~B})$ & 170 \\
\hline Elimination half-life (hrs) & $2-4$ & $4-6$ & 3 \\
\hline Clearance (ml/min) & No data & $130-200$ (A) $140-250$ (B) & 600 \\
\hline
\end{tabular}


Although some receptor affinity has been noted for both monoamineoxidase (MAO) type A and MAO type $\mathrm{B}$ receptors, clinical activity is unlikely to be due to MAO inhibition. ${ }^{18,20,21}$ Another possible mechanism includes serotonin reuptake inhibition, but the concentrations required to achieve this effect in vivo may not be achievable. ${ }^{18}$ Other receptors inhibited by $H$. perforatum crude extracts include gammaaminobutyric acid (GABA) type A and GABA type B benzodiazepine, and inositol triphosphate. ${ }^{20}$ For the pharmacokinetics of hypericin and pseudohypericin, see Table $3 .{ }^{18}$ Other constituents may alter the pharmacokinetics of the plant as a whole.

Reports of clinical efficacy for St. John's wort in patients with mild to moderate depression have ranged up to $81 \%$ in randomized double-blind trials primarily using the LI- 160 extract standardized to $0.3 \%$ hypericin. A review comparing St. John's wort to synthetic antidepressants found that St. John's wort was equally effective and induced a lower incidence of side effects. ${ }^{22}$ The synthetic antidepressants may not have been adequately dosed in these trials. Most of the St. John's wort trials enrolled small numbers of patients, but the aggregate number of patients treated in clinical trials was more than 1,500. A metaanalysis concluded that St. John's wort was significantly more effective than placebo, with an odds ratio of 2.67 and $95 \% \mathrm{CI}$ of 1.78 to $4.01 .{ }^{23}$ Comparisons to newer antidepressants such as the selective serotonin reuptake inhibitors were not located.

Overall, the adverse effects of St. John's wort in clinical trials have been mild, with an incidence similar to placebo $(4 \%-11 \%)$ and certainly less than that associated with tricyclic antidepressants. Mild stomach irritation appears to be the most common side effect $(0.6 \%)$, along with allergic reactions $(0.5 \%)$. Photosensitization has been reported, as well as one case report of polyneuropathies in areas of the body exposed to the sun. ${ }^{18,24}$. No drug interactions have been published, but St. John's wort may decrease the international normalized ratio in patients taking warfarin (unpublished data). Because St. John's wort was reported to affect MAO receptors and serotonin levels, caution has been advised in mixing these agents with drugs known to interact with MAOIs or selective serotonin reuptake inhibitors. Given more recent information on the mechanisms of St. John's wort activity, this precautionary advice may not be necessary. ${ }^{17}$ In mice, $H$. perforatum extracts have potentiated the effects of alcohol and antagonized reserpine. ${ }^{17,18}$

The recommended dose of St. John's wort is $300 \mathrm{mg}$ three times daily up to a maximum of $2,000 \mathrm{mg}$ daily. ${ }^{6}$ Patients should be advised to take products most reflective of the product used in the clinical trials (LI-160) that was standardized to contain at least $0.3 \%$ hypericin. Based on current research, the best products may be those standardized to $0.3 \%$ hypericin and $6 \%$ hyperforin. ${ }^{19}$

St. John's wort has shown clinical efficacy compared to placebo for the treatment of mild to moderate depression, with a low incidence of side effects. Specifically, St. John's wort has not been reported to induce sexual dysfunction. It has not been studied in severe depression. For patients with mild to moderate depression who express the desire to use a less toxic alternative, a two-month trial of St. John's wort may be warranted. Until more information is available, St. John's wort should probably not be combined with prescription antidepressants because the mechanism of action remains unknown.

\section{GINSENG}

Although several species of ginseng have been used in Asian medicine, the Asian, Korean, and white ginseng (Panex ginseng) have been most commonly used as a general tonic, especially for men. ${ }^{25}$ Other ginsengs include American ginseng (P. quinquefolium) and Siberian ginseng (Eleutherococcus senticosus), which is not actually a ginseng species. The common factor among these three plants is the presence of ginsenosides, which are triterpenoid saponins. From a medicinal chemistry point of view, the ginsenosides from all three ginsengs are very similar. However, from the historical perspective of traditional Asian medicine, all three have very distinct properties and would be used for different purposes

The ginsenosides are designated $\mathrm{Rg}$, $\mathrm{Rc}, \mathrm{Rd}, \mathrm{Rb}_{1}, \mathrm{Rb}_{2}$, and Rbo. Separately, these ginsenosides have demonstrated opposing pharmacological action. ${ }^{26}$ For example, Rgı raises blood pressure and acts centrally as a stimulant; however, $\mathrm{Rb}_{1}$ lowers blood pressure and acts centrally as a depressant. Ginseng acts at the pituitary adrenal axis, increasing resistance

Table 3. Pharmacokinetics for Hypericin and Pseudohypericin from a Single $300 \mathrm{mg}$ Hypericum Extract Dose

\begin{tabular}{l|c|c}
\hline \multicolumn{1}{c|}{ Pharmacokinetic parameter } & Hypericin & Pseudohypericin \\
\hline Area under the curve $(\mathrm{ng}$ min/mL) & $1,920(978-2,720)$ & $1,900(1,150-2,600)$ \\
\hline Time to peak concentration $(\mathrm{hrs})$ & $5.2(4-6)$ & $2.7(2-3.5)$ \\
\hline Peak concentration $(\mathrm{ng} / \mathrm{mL})$ & $1.5(1-2)$ & $2.7(2-5.4)$ \\
\hline Elimination half-life $(\mathrm{hrs})$ & $24.8(10.3-37)$ & $16.3(6.3-30.5)$ \\
\hline
\end{tabular}

Source: St. John's wort: Hypericum perforatum quality control, analytical and therapeutic monograph. HerbalGram 1997; 40 (American Herbal Pharmacopoeia Therapeutic Compendium) 
to stress, functioning as an adaptogen. Ginseng also affects metabolism, skin tone, muscle tone, and hormonal balance. The whole root and individual ginsenosides can induce hypoglycemia. ${ }^{25}$ Research has linked an organ protective effect in ginseng with the ability to enhance nitric oxide synthesis in the endothelium of the lung, heart, kidney, and corpus carvenosum. ${ }^{27}$ This effect on the corpus carvenosum may lend credence to the historical use of ginseng as an aphrodisiac.

Commission $\mathrm{E}$ has approved labeling for ginseng as a tonic for invigoration and fortification in times of fatigue and debility. ${ }^{6}$ Ginseng also has received approved labeling for treatment of declining work capacity and concentration as well as for convalescence. Currently, Asian ginseng is said to be used by Chinese athletes to enhance physical performance by improving or prolonging stamina. ${ }^{28}$ However, two studies have failed to confirm any beneficial effect on exercise. ${ }^{29,30}$

Side effects include nervousness and excitation when therapy is initiated. If tolerance does not develop, these effects will abate with reduced dosages. ${ }^{25}$ Long-term use has been associated with an inability to concentrate. Other adverse effects reported over a two-year period in 133 patients included stimulation (100\%), morning diarrhea (35\%), skin eruptions (25\%), sleeplessness (20\%), nervousness (19\%), hypertension (17\%), euphoria (14\%), edema (11\%), decreased appetite $(5 \%)$, depression (4\%), hypotension (4\%), and amenorrhea (3\%). ${ }^{31.32} \mathrm{~A}$ single case report of diffuse mammary nodularity has been published, as has vaginal bleeding in an elderly woman..$^{25}$

The dose is 1-2 grams of root daily according to Commission E. ${ }^{6}$ Products should be standardized to $1.5 \%$ ginsenosides calculated as the $\mathrm{Rg}_{1}$. Reports of potential drug interactions include monoamine oxidase inhibitors (maniclike symptoms) and caffeine (hypertension). ${ }^{17}$ Insulin and warfarin doses may need to be adjusted.

Clinical studies documenting ginseng's effectiveness are lacking. Patients wishing to use ginseng as a general tonic should be counseled to set targeted outcomes (e.g., increasing energy or sexual potency). Patients then could take the recommended standardized dose for one to two months and note any changes in targeted outcomes or appearance of adverse effects.

\section{GARLIC}

Garlic, like onion, is in the Lily family. ${ }^{25}$ An amino acid derivative extracted from the bulb, alliin (S-allyl-L-cysteine sulfoxide), is the parent substance that in the presence of alliinase forms allicin. ${ }^{33}$ Alliin is odorless, but allicin provides the characteristic garlic odor. Allicin has been postulated to be the primary active constituent responsible for garlic's ability to decrease cholesterol, reduce high blood pressure, increase smooth muscle tone of the intestines, and act as an antibacterial agent. Alliin has some antiplatelet and cholesterol-lowering effects, but no antibacterial effects. Allicin is unstable and self-condenses to ajoene. Ajoerie, which shows antithrombotic activity and also may have antifungal activity, inhibits fibrinogen-induced platelet aggregation..$^{34,35}$

Because of allicin's instability, Commission E has approved only products that are fresh garlic or the equivalent of fresh garlic. ${ }^{6}$ Extracts that cannot assure allicin content such as aged garlic (Kwai/ $\Subset)$ and garlic powders may lack efficacy. Even carefully dried products that preserve the allicinase to convert alliin to allicin must be enteric coated to prevent the enzyme's degradation in the stomach acid. Enteric-coated garlic that provides sufficient quantities of alliin and allicinase to the lower gastrointestinal tract to prevent stomach acid from destroying the allicinase may meet Commission E labeling standards, but published data to support their efficacy are lacking. Commission E-approved labeling for garlic products meeting its standards include treatment of hypercholesterolemia and prevention of artherosclerosis. ${ }^{6}$ Garlic also has been used to treat high blood pressure, colds, and chronic infections.

In four clinical trials using fresh garlic or freshly made garlic extracts, garlic was given in doses of 10-30 grams daily for three weeks to two months.$^{33}$ These trials showed a cholesterol-lowering effect ranging from $10 \%-18 \%$. These doses, unfortunately, translate to ingestion of two to seven cloves of fresh garlic daily.

Two recent studies using commonly marketed garlic extracts (Kwai/ $Æ$ and Tegra/ $Æ$ ) found that neither product lowered cholesterol significantly. ${ }^{36,37}$ The diallyl disulfide and diallyl trisulfide formed from alliin and allicin were reported by the authors to be present in their samples and were reflective of the active constituents. ${ }^{37}$ This concept was challenged by Lawson in a letter to the editor. ${ }^{38}$

Adverse effects are mild and self-limiting, including heartburn, flatulence, and related gastrointestinal problems at five or more cloves of garlic daily. A single case report of an elderly gentleman consuming four cloves of fresh garlic a day adds credence to the food's antiplatelet effect. ${ }^{39}$ The man developed a spontaneous spinal hematoma. His prothrombin time and partial thromboplastin times were normal, but his bleeding time was prolonged. After three days of hospital admission without fresh garlic ingestion, his bleeding time was back to normal. He was taking no other drugs and had no other risk factors for bleeding. Drug interactions are potentially problematic secondary to the platelet-lowering effects, including problems with warfarin. ${ }^{17}$ The approved labeling dose from the Commission E monographs is 4 grams of fresh garlic or its equivalent daily-approximately one clove.

Given the evidence in published trials that some garlic extracts may not be effective in reducing cholesterol, patients wishing to use dietary means to lower cholesterol 
could, in addition to lowering fat intake, increase the amount of fresh garlic in their diet to about one garlic clove daily.

\section{ECHINACEA}

Echinacea products are manufactured from any or a combination of three species of echinacea grown in the U.S. (listed previously). ${ }^{25}$ The roots and plant contain a wide variety of chemical constituents including alkylamides, alkaloids, caffeic acid derivatives, chicoric acid, essential oils, flavonoids, polyactylenes, and polysaccharides. ${ }^{25,26}$ Whether the action of echinacea can be attributed to one constituent or requires multiple constituents (i.e., the whole plant or root) is not known. Constituents of echinacea have been shown to have immunostimulatory, antiinflammatory, bacteriostatic, bactericidal, and free radical scavenging effects. ${ }^{26}$ Specific constituents have been found to promote tissue granulation, others to have an oncolytic action or adjunctive effect on cytotoxic macrophages. Commercial products may contain alcohol extracts of the roots, dried extracts of the fresh pressed juice of the aerial parts of the plant, or a combination.

Many randomized controlled clinical trials have been published on echinacea, but have primarily appeared in the German literature. A recent study appeared in American literature on using echinacea root extracts for the prevention of upper respiratory tract infections. ${ }^{40}$ Two different echinacea extracts (E. angustifolia or E. purpurea roots) were compared to placebo in 302 volunteers free of illness. The volunteers were asked to take 50 drops of their assigned preparation twice daily for 12 weeks. The primary outcome measure was time to first occurrence of a respiratory illness. No difference was found. The only statistically significant differences in secondary outcome measures were that more patients in the E. angustifolia group believed they had benefited and correctly guessed whether they had been allocated to treatment versus placebo. Neither of these extracts is an approved herb, according to the Commission E monographs. ${ }^{6}$ Other studies have used the Commission E-approved products and found beneficial effects. ${ }^{41 .+2}$ For one, Echinagard $Æ$ (an alcoholpreserved solution of fresh pressed juice of $E$. purpurea) or matching placebo was randomly given to 120 patients with acute, uncomplicated upper airway infections for 10 days. ${ }^{41}$ Time to improvement was statistically different by Log rank test $(\mathrm{P}<0.0001)$. Most patients experienced symptom improvement within four days compared to nine days with placebo. A metaanalysis has been published in Germany that includes six randomized, double-blind, placebo-controlled trials studying the efficacy of echinacea specifically for respiratory tract infection prophylaxis and treatment. ${ }^{43}$ The authors concluded that symptoms and duration of symptoms were improved over placebo. For prophylaxis, echinacea also demonstrated beneficial effects. The validity of the research design of the studies included in the metaanalysis, however, has been questioned. Although research exists supporting the use of echinacea for the prophylaxis and treatment of upper respiratory tract illnesses, well-designed clinical studies are needed to confirm these reports.

The Commission E monographs approved labeling of $E$. pallida root extracts for the supportive therapy of influenzalike infections. ${ }^{6}$ The monographs also approved labeling of $E$. purpurea as the expressed juice of aerial parts of the plant for the supportive therapy for colds and chronic infections of the respiratory tract and lower urinary tract. A parenteral preparation of $E$. purpurea is used in Germany for the same indications. E. angustifolia is listed as an unapproved herb in the Commission E monographs.

Serious toxicities to echinacea have not been reported despite its widespread use. A potential allergic reaction has been reported ${ }^{44}$ in a woman who had been taking echinacea as well as other dietary supplements for prophylaxis on an irregular basis for two to three years. On the morning of the reaction she ingested several vitamin preparations, a garlic and onion preparation, and evening primrose oil. When she took double the recommended dose of a product containing E. angustifolia herb and E. purpurea root, she experienced anaphylactic symptoms and was hospitalized. The parenteral form of E. purpurea has been associated with fever, nausea, and vomiting. ${ }^{6}$

The Commission E-approved labeling dose for the tincture of E. pallida root is the equivalent to $900 \mathrm{mg}$ of the root daily. ${ }^{6}$ Approved dosage labeling for the expressed juice of $E$. purpurea is 6 to $9 \mathrm{ml}$ daily. The Commission-approved labeling also recommends that the E. purpurea herbal products not be taken for longer than eight weeks. Some references. have recommended that echinacea products be taken as a 10-days-on, five-days-off schedule. ${ }^{45}$ This recommendation may have been based on erroneous interpretation of a German article that showed declining phagocytoses after 10 days. In this study, however, the echinacea had been stopped at day five, with the outcome followed for five more days. Hence declining effects would be expected over the remaining five days of data collection. Children's doses are not available, although one pediatrician has estimated doses of $y_{4}$ to 1 dropperful of a tincture three to four times daily diluted in water or fruit juice. ${ }^{46}$ Because Commission E makes a distinction between the three echinacea products and studies. supporting this distinction have been published, patients should be advised to take either the fresh-pressed juice of $E$. purpurea or E. pallida root extracts.

\section{SAW PALMETTO}

Saw palmetto is the dwarf American palm tree. ${ }^{47}$ The berries of the saw palmetto tree historically have been used for genitourinary problems, to increase sperm production in men and increase breast size in women, and to stimulate sexual vigor. ${ }^{25}$ Early in this century, saw palmetto was used as a tea (i.e., hot-water extract) to treat benign prostatic 
hyperplasia (BPH), but was dropped from the National Formulary because of questionable efficacy. The Commission $\mathrm{E}$ monograph specifies that the lipophilic portion of the berry contains the active constituents. ${ }^{6}$ However, the exact active constituent is not known. The commercial preparation in Europe (Permixon/E) contains a lipidic liposterolic extract. ${ }^{48}$

Pharmacodynamic efiects of the liposterolic extract include inhibition of type 1 and type 2 isoenzymes of 5-alphareductase as well as blocking the binding of dihydrotestosterone to cytosolic androgen receptors in prostatic cells. ${ }^{48}$ Although isolated sitosterols have weak estrogenic activity, they are unlikely to be active when taken orally. Limited pharmacokinetic data for saw palmetto have been published. ${ }^{48}$ Twelve healthy males were given $320 \mathrm{mg}$ of the plant extract orally. The mean peak plasma level of a component with a retention time of 26.4 minutes on HPLC was $2.6 \mathrm{mg} / \mathrm{L}$ at 1.5 hours. The mean area under the curve was $8.2 \mathrm{mg} /$ Lhour, with an elimination half-life of 19 hours.

More than 30 clinical trials have studied the clinical efficacy of saw palmetto extract for the treatment of BPH. Almost half of these were uncontrolled, unblinded trials. A recent review of 18 randomized controlled trials concluded that many of the studies were flawed and were of short duration. ${ }^{49}$ Overall, however, the authors concluded that studies on saw palmetto for the treatment of BPH did provide evidence of efficacy in improving urologic symptoms and flow measures. Also, compared to those on finasteride, patients on saw palmetto had similar improvement in urinary tract symptoms and urinary flow and experienced fewer adverse effects.

Adverse effects are infrequent, occurring in most clinical trials in less than $4 \%$ of the subjects. ${ }^{+9}$ The most commonly reported disturbance is gastrointestinal upset (1.3\%), which can be minimized by taking doses with food. High doses have been associated with headache and diarrhea. One case report has been published in which a 65 -year-old man who ingested a combination product (Prostata/E) that contained saw palmetto developed cholestatic hepatitis. ${ }^{50}$ In the comparative trial with finasteride, saw palmetto did not cause the decreased libido and impotence reported with finasteride. ${ }^{49}$

The recommended dose is $160 \mathrm{mg}$ twice daily of a liposterolic extract of the saw palmetto berries or 1 to 2 grams of the dried whole berry.

Given the potential efficacy of saw palmetto in the treatment of BPH and its lower toxicity compared to finasteride, a trial of a standardized liposterolic extract may be beneficial particularly in men who have toxicities from finasteride or cannot tolerate the alpha antagonists (e.g., doxazosin).

\section{KAVA}

Kava root has been used for centuries in Polynesia as a ceremonial beverage that promotes relaxation. ${ }^{51}$ Native Polynesians masticate or pound the root, knead it with water, then strain the resultant extract into a bowl; the extract is then orally ingested. The traditional use of kava varies within the different areas of Oceania. The cultures on some islands use it solely for ceremonial purposes, others also use it as a social drink, and some also use it medicinally to soothe the nerves, induce sleep, counteract fatigue, treat congestion in the urinary tract, treat asthma and rheumatism, and for weight loss. The products available in the United States are typically powdered root, extracts, or tinctures.

The pharmacology of kava has not been well characterized. The central nervous system activity of kava may be related to two series of closely related arylethylene pyrones (lactones), substituted 5,6-dihydro-alpha-pyrones and substituted alpha-pyrones, which are found in the roots and rhizomes of the plant as 5\%-9\% of the total pyrone content. ${ }^{25,51}$ These pyrones are poorly soluble in water, but much more soluble in alcohol. The kava pyrones have a weak narcotic action via a nonopiate pathway; they paralyze sensory nerves, and they stimulate and then paralyze smooth muscle with increasing doses. Kava use can improve cognitive function, and kava pyrones can induce a mephenesin-like skeletal muscular relaxation in all species of lab animals, most notably in being able to protect mice from the convulsions caused by what should be toxic doses of strychnine. ${ }^{52}$ Large doses of kava pyrones produced ataxia and ascending paralysis without loss of consciousness, followed by complete recovery. In lab animals, death resulting from a large dose of kava pyrones was caused by respiratory failure. ${ }^{51}$ Chewing kava produces a numbness of the oral mucosa (i.e., a local anesthetic effect) comparable to that of cocaine and longer lasting than benzocaine..$^{25}$

A standardized kava extract called WS 1490 (Laitan) or placebo was administered to 58 patients with anxiety syndrome unrelated to psychiatric disorders. ${ }^{53}$ In this doubleblind study, patients took a dose of $100 \mathrm{mg}$ three times daily. Therapeutic efficacy was primarily evaluated using the Hamilton Anxiety Scale (HAM-A) at baseline and after one, two, and four weeks of therapy. After one week the HAM-A total scores were lower and continued to decrease over the study period. Only an abstract is available, and it does not detail the statistical significance of the change or the comparison with placebo

A second placebo-controlled trial also using the extract called WS 1490 extended the observation period in another? group of patients to 24 weeks. ${ }^{5+}$ One hundred and one patients with DSM III-R-defined anxiety from nonpsychotic origin were randomized to WS 1490 or matching placebo. The primary test measurement to show efficacy was the HAM-A. Baseline characteristics were equally distributed. A statistically significant difference between WS 1490 and placebo was noted at eight weeks $(\mathrm{p}=0.02)$ with the difference in total scores widening over the next 16 weeks ( $<<0.001$ at 24 weeks). 
Chronic prolonged ingestion has been associated with kava dermopathies characterized by dry scaly skin appearing on the back of the hands, forearms, back, shins, and soles of the feet. ${ }^{55}$ The scales are called kani. Whether this is an allergic reaction or not remains to be determined. The only effective treatment is to discontinue ingestion.

A drug interaction between kava (100 mg three times daily for three days) and alprazolam has been reported, with the individual exhibiting symptoms of lethargy and disorientation. ${ }^{56}$ In normal healthy adults (10 men and 10 women), kava (WS 1490) in a dose of $300 \mathrm{mg}$ daily for eight days did not appear to alter performance parameters when combined with alcohol ( $0.5 \%$ blood concentration) ${ }^{57}$ This test, conducted in a placebo-controlled, double-blind design, is in contrast to other reports that note a marked drug interaction between kava and alcohol. ${ }^{25}$ The American Herbal Products Association approved cautionary labeling for kava products to include the recommendation to limit the daily dose of kava to $300 \mathrm{mg}$ and to warn the consumer that "excessive consumption may impair ability'to drive or operate heavy machinery." 58 Kava may reduce the efficacy of levodopa in Parkinson's patients. ${ }^{59}$

The recommended dose is $100 \mathrm{mg}$ three times daily of a product standardized to $60-120 \mathrm{mg}$ kavalactones. ${ }^{6}$ The Commission $\mathrm{E}$ monograph advises that kava not be taken for longer than three months unless on the advice of a physician.

Kava appears to be an effective antianxiety agent. One should be cautious in interpreting the available data and not assume that kava is not addicting. Short-term use for daytime anxiety could be appropriate. Patients should be warned about a possible sedating effect and that combining with other CNS depressants, including alcohol, is not advisable.

\section{VALERIAN}

Valerian is an aromatic root used historically as a perfume and a sedative. ${ }^{25}$ Some find the root's odor disagreeable. Valerian contains valepotriates, alkaloids, and a volatile oil with sesquiterpenes (valerenic acids). Many of the products used medicinally do not contain the valepotriates because valepotriates are heat labile and chemically unstable. ${ }^{6}$ Both valepotriates and valerenic acids cause sedation and are found in the water-soluble fraction in very small quantities. The water-soluble fraction shows the greatest clinical activity. Activity is thought to be due to an additive effect of constituents from the whole plant rather than to one or two particular constituents. The biochemical action of valerian remains unknown at this time.

Twenty-seven subjects received either VALERINA NATT (a standardized extract containing $400 \mathrm{mg}$ of valerian plus two other plant extracts from Flores humuli and Herba melissae) or an identical tablet containing the same amounts of the other two plant extracts but only $4 \mathrm{mg}$ of valerian root, in a randomized, cross-over design. ${ }^{60} \mathrm{~A}$ single dose of first one, then the other, preparation was taken at bedtime on two consecutive nights. The morning after the second night the subjects were asked to respond to a rating scale on the quality of sleep and whether one preparation was better, worse, or the same as the other. A sign test was used to test for significance. Of 27 subjects, 21 subjectively rated the test preparation to be better than the control preparation $(p<0.001)$. The test preparation improved the sleep in 24 of 27 subjects compared to three of 27 subjects who took the control preparation. The order in which the preparations were taken did not appear to influence the results.

Hova $Æ$ contains valerian (water extract) $60 \mathrm{mg}$ and hop flower extract $30 \mathrm{mg}$ per tablet. Hova $Æ$ was compared to placebo (finely ground brown sugar) and a $400 \mathrm{mg}$ valerian extract. ${ }^{61}$ All came packaged in matching capsules. Each of 166 subjects received nine doses, three of each preparation. The subjects took each of the nine doses on nonconsecutive nights and rated them on a standardized questionnaire the next morning. The sample included subjects who reported being "good sleepers" (52\%), who quickly fell asleep (73\%), and who had less than two awakenings per night; 128 subjects completed the study protocol. Sleep latency was shortened in $35 \%$ of the subjects taking valerian ( $p<0.05$ compared to placebo, not significant compared to Hova $Æ$ ). Sleep latency was increased in $22 \%$, but this figure was not significantly different from that of placebo. Hova $Æ$ shortened sleep latency, but the difference was not statistically different from placebo. Neither Hova/Æ, valerian extract, nor placebo affected the quality of sleep in the subjects who did not have sleep disorders. However, in patients who reported sleep difficulties before the study, $51 \%$ improved in sleep quality ( $p<0.05$ compared to placebo) when taking valerian extract. Subjects with poor sleep noted fewer nighttime awakenings, but the difference compared to placebo was not significant. Morning drowsiness was greatest with Hova E ( $p<0.01$ compared to placebo and $p<0.05$ compared to valerian extract). Valerian was equal to placebo in morning drowsiness.

Valerian can cause morning drowsiness if the dose is too high. ${ }^{25}$ In animals, intraperitoneal doses up to $1600 \mathrm{mg} / \mathrm{kg}$ and oral doses to $4600 \mathrm{mg} / \mathrm{kg}$ induced ataxia, hypothermia, and increased muscle relaxation but no deaths. In controlled clinical trials in humans, headache; excitability, uneasiness, and cardiac disturbances were reported. In animals, additive pharmacological effects with other sedative/hypnotics were not found. No reports of drug interactions have been reported in humans.

The dose ranges from 2-3 grams for the dried root to $150-200 \mathrm{mg}$ of the dry powdered extract taken 45 minutes before bedtime. ${ }^{6}$ Valerian can be taken as a tea (if palatability is not a problem), a tincture, or a fluid extract.

Valerian does cause a sedative effect. Whether this makes valerian an effective hypnotic remains to be determined. For 
patients who wish to use a hypnotic other than a benzodiazepine, antihistamine, or antidepressant, or who have used these products with limited or no success, valerian is worth a short trial. Patients should be cautioned about the potential for a morning hangover effect and the need to decrease the dose if this occurs: Despite the lack of published reports of problems, patients should be advised to be cautious about combining valerian with alcohol.

\section{SUMMARY}

The evidence that supports the efficacy and safety of herbal supplements varies greatly between products. Some of the herbal supplements reviewed appear to have clear places in therapy (e.g., saw palmetto). Others need more research into the most active standardized product and completion of well-done clinical trials to establish efficacy. Pharmacists knowledgeable about herbal supplements can work better with their patients to help them use these products safely and effectively.

\section{References}

1. Eisenberg DM, Davis RB, Ettner SL, et al. Trends in alternative medicine use in the United States, 1990-1997: results of a follow-up national survey. JAMA 1998; 280: 1569-75

2. Brevoort P. The booming U.S. botanical market: a new overview. HerbalGram 1998; 44: 33-46.

3. Hepler CD, Angaran DM. The nature of caring. In: Pharmaceutical care New York: Chapman \& Hall, 1996.

4. Astin JA. Why patients use alternative medicine: results of a national study. JAMA 1998; 279: 1548-53.

5. FDAVCFSAN Dietary Supplement Health and Education Act of 1994 http://vm.cfsan.fda.gov/ dms/dietsupp. August 24, 1996.

6. Blumenthal M, ed. The complete German Commission E monographs: therapeutic guide to herbal medicines. Austin, TX: American Botanical Council, 1998.

7. Van Beek TA, Bomardelli E, Morazzoni P, et al. Ginkgo biloba L.

Fitoterapia 1998; 69: 195-244.

8. Kleijnen J, Knipschild P. Ginkgo biloba. Lancet 1992; 340: 1136-39.

9. Braquet P, Hosford D. Ethnopharmacology and the development of natural PAF antagonists as therapeutic agents. J Ethnopharmacol 1991; 32: 135-39. 10. LeBars PL, Katz MM, Berman N, et al. A placebo-controlled, doubleblind randomized trial of an extract of ginkgo biloba for dementia. JAMA 1997; 278: 1327-32.

11. Blumenthal M. German government limits ginkgolic acid levels in ginkgo leaf extracts. HerbalGram 1997; 41: 29.

12. Kanowski S, Herrmann WM, Stephan K, et al. Proof of efficacy of the Ginkgo biloba special extract EGb 761 in outpatients suffering from mild to moderate primary degenerative dementia of the Alzheimer type of multiinfarct dementia. Pharmacopsychiat. 1996; 29: 47-56.

13. Meyer B. A multicentre, randomized, double-blind drug versus placebo study of Ginkgo biloba extract in the treatment of tinnitus. La Presse Medicale 1986; 15: 1562-64. (abstract only)

14. Haguenauer JP, Cantenot F, Koskas H, et al. Treatment of disturbances of equilibrium with Ginkgo biloba extract: a multicentre, double-blind, drug versus placebo study. La Presse Medicale 1986; 15: 1569-72. (abstract only) 15. Semlitsch HV, Anderer P, Saletu B, et al. Cognitive psychophysiology in nootropic drug research: effects of Ginkgo biloba on event-related potentials
(P300) in age-associated memory impairment. Pharmacopsychiatry 1995 ; 28: $134-42$

16. Rai GS, Shovlin C, Wesnes KA. A double-blind, placebo-controlled study of Ginkgo biloba extract ("tanakan") in elderly outpatients with mild to moderate memory impairment. Current Medical Research \& Opinion 1991; 2: $350-55$

17. Brinker F. Herb contraindications and drug interactions. Sandy, OR: Eclectic Medical Publications, 2nd ed., 1998.

18. Upton R, ed. St. John's wort: Hypericum perforatum quality control, analytical and therapeutic monograph. HerbalGram 1997; 40 (American Herbal Pharmacopoeia Therapeutic Compendium): 1-32.

19. Chatterjee SS, Noldner M, Koch E, et al. Antidepressant activity of Hypericum perforatum and hyperforin: the neglected possibility.

Pharmacopsychiatry 31 Suppl 1: 7-15, June 1998.

20. Cott JM. In vitro receptor binding and enzyme inhibition by Hypericum perforatum extract. Pharmacopsychiat 1997; 30: 108-12.

21. Müller WE, Rolli M, Schafer C, Hafner U. Effects of hypericum extract (LI160) in biochemical models of antidepressant activity. Pharmacopsychiat 1997; 30: 102-07.

22. Volz HP. Controlled clinical trials of hypericum extracts in depressed patients-an overview. Pharmacopsychiatry 1997; 30 Suppl 2: $72-76$.

23. Linde K, Ramirez G, Mulrow CD, et al. St John's wort for depressionan overview and meta-analysis of randomised clinical trials. BMJ 313(7052): 253-58, August 1996

24. Bove GM. Acute neuropathy after exposure to sun in a patient with St. John's Wort. Lancet 1998; 352: 1121-22.

25. Burnham TH, ed. Review of natural products. Facts and Comparisons. St. Louis, MO.

26. Bisset NG, ed. Herbal drugs and phytopharmaceuticals: a handbook for practice on a scientific basis. Boca Raton, GA: Medpharm Scientific Publishers, CRC Press, 1994

27. Gillis CN. Panax ginseng pharmacology: a nitric oxide link? Biochemical Pharmacology 1997; 54: 1-8.

28. Bahrke MS, Morgan WP. Evaluation of the ergogenic properties of ginseng. Sports Medicine 1994; 18: 229-48.

29. Engels HJ, Wirth JC. No ergogenic effects of ginseng (Panax ginseng C.A. Meyer) during graded maximal aerobic exercise. J Am Dietetic Association 1997; 97: 1110-15.

30. Morris AC, Jacobs I, McLellan TM, et al. No ergogenic effect of ginseng ingestion. International J Sport Nutrition. 1996; 6: 263-71.

31. Siegel RK. Ginseng abuse syndrome: problems with the panacea. JAMA 1979; 241: 1614-15.

32. Hammond TG, Whitworth JA. Adverse reactions to ginseng. Medical Journal of Australia 1981; 1: 492.

33. Kleijnen J, Knipschild P, ter Riet G. Garlic, onions and cardiovascular risk factors. A review of the evidence from human experiments with emphasis on commercially available preparations. British Journal of Clinical Pharmacology. 1989; 28: 535-44.

34. Apitz-Castro R, Escalante J, Vargas R, et al. Ajoene, the antiplatelet principle of garlic, synergistically potentiates the antiaggregatory action of prostacyclin, forskolin, indomethacin and dypiridamole on human platelets. Thrombosis Research. 1986; 42: 303-11.

35. Apitz-Castro R, Ledezma E, Escalante J, et al. The molecular basis of the antiplatelet action of ajoene: direct interaction with the fibrinogen receptor. Biochemical \& Biophysical Research Communications 1986; 141: 145-50.

36. Berthold HK, Sudhop T, von Bergmann K. Effect of a garlic oil preparation on serum lipoproteins and cholesterol metabolism: a randomized controlled trial. JAMA 1998; 279: 1900-02.

37. Isaacsohn JL, Moser M, Stein EA, et al. Garlic powder and plasma lipids and lipoproteins: a multicenter, randomized, placebo-controlled trial. Arch Intern Med. 1998; 158: 1189-94.

38. Lawson LD. Effect of garlic on serum lipids (letter). JAMA 1998; 280: 1568 39. Rose KD, Croissant PD, Parliament CF, et al. Spontaneous spinal epidur- 
al hematoma with associated platelet dysfunction from excessive garlic ingestion: a case report. Neurosurgery 1990; 26: 880-82.

40. Melchart P, Wlather E, Linde K, et al. Echinacea root extracts for the prevention of upper respiratory tract infections. Arch Fam Med 1998; 7: 541-45. 41. Hoheisel $O$, Sandberg $M$, Bertram S, et al. Echinagard treatment shortens the course of the common cold: a double-blind, placebo-controlled clinical trial. European Journal of Clinical Research 1997; 9: 261-68.

42. Berg A, Northoff $H_{1}$.Konig D, et.al. Influence of Echniacin (EC31), treatment on the exercise-induced immune response in athletes. Journal of Clinical Research. 1998; 1: 367-80.

43. Gelman CR, Rumack BH, Sayre NK, eds. DRUGDEX system.

Englewood, CO: MICROMEDEX, Inc., 1998.

44. Mullins RJ. Echinacea-associated anaphylaxis. Med J Australia. 1998; 168: $170-71$

45. Bergner P. Echinacea myth: phagocytosis not diminished after ten days. Medical herbalism: a clinical newsletter for the herbal practitioner. 1994; 6: 1 . 46. Kemper KJ. Seven herbs every pediatrician should know. Contemporary Pediatrics 1996; 13: 79-91

47. Plosker GL, Brogden RN. Serenoa repens (Permixon). A review of its pharmacology and therapeutic efficacy in benign prostatic hyperplasia. Drugs \& Aging 1996; 9: 379-95.

48. Paubert-Braquet $M$, Cousse H, Raynaud JP, et al. Effect of the lipidosterolic extract of Serenoa repens (Permixon) and its major components on basic fibroblast growth factor-induced proliferation of cultures of human prostate biopsies. European Urology 1998; 33(3): 340-47.

49. Wilt TJ, Ishani $\AA$, Stark $G$, et al. Saw palmetto extracts for ireatment of benign prostatic hyperplasia: a systematic review. JAMA 1998; 280: 1604-09. 50. Hamid S, Rojter S, Vierling J. Protracted cholestatic hepatitis after the use of prostata. Annals of lnternal Medicine 1997; 127: 169-70.
51. Singh YN. Kava: an overview. J Ethnopharmacol 1992; 37: 13-45. 52. Heinze HJ, Munthe TF, Steitz J, et al. Pharmacopsychological effects of oxazepam and kava-extract in a Visual Search Paradigm Assessed with Eventrelated Potentials. Pharmacopsychiat. 1994; 27: 224-30 (abstract only). 53. Kinzler E, Kromer J, Lehmann E. Effect of a special kava extract in patients with anxiety-, tension-, and excitation states of non-psychotic genesis. Arnzéimet Forsch 1991; 41: 584-88 (abstract only).

54. Volz. HP, Kieser M. Kava-kava extract WS 1490 versus placebo in anxiety disorders: a randomized, placebo-controlled, 25 weeks outpatient trial. Pharmacopsychiatry 1997; 30: 1-5.

55. Norton SA, Ruze P. Kava dermopathy. Journal of the American Academy of Dermatology 1994; 31: 89-97.

56. Almeida JC, Grimsley EW. Coma from the health food store: interaction between kava and alprazolam (letter). Ann Internal Med 1996; 125: 940-41. 57. Herberg KW. Effect of kava-special extract WS 1490 combined with ethyl alcohol on safety-relevant performance parameters. Blutalkohol 1993; 30: 96-105 (abstract only).

58. Anon. AHPA's recommended label language for kava products. HerbalGram 1998; 42: 25.

59. Schelosky L, Raffauf C, Jendroski K, Poewe W. Kava and dopamine antagonism [letter]. J Neurology, Neurosurgery \& Psychiatry 1995; 58: 639-40. 60 . Lindahl $O$, Lindwall L. Double-blind study of a valerian preparation. Pharmacol Biochem Behav 1989; 32: 1065-66.

61. Leathwood PD, Chauffard F, Heck E, et al. Aqueous extract of valerian root (Valeriana officinalis L.) improves sleep quality in man. Pharmacol Biochem Behav 1982; 17: 65-71.

Turn to page 369 for the CE Exam. 
Upon completion of this article, the successful participant should be able to:

1. Define DSHEA and list the implications of that act for pharmacist and patients. $=$

2. Given an herbal supplement, determine an acceptable indication and dose for that indication.

3. Given an herbal supplement, list the common or serious side effects induced by that supplement.

4. Given an herbal supplement, provide information applicable for patient counseling.

\section{SELF-ASSESSMENT QUESTIONS}

1. Which one of the following statements provides the implications of the Dietary Supplement Health and Education Act of 1994?

a. Defines dietary supplements as drugs to be evaluated for safety and efficacy by the FDA.

b. Provides good manufacturing procedures standards for the manufacturing and marketing of dietary supplements.

c. Allows sales of botanical and other natural products as dietary supplements.

2. Ginkgo has demonstrated efficacy in randomized controlled trials for which one of the following indications?
a. Alzheimer's disease
b. Benign prostatic hypertrophy
c. Depression
d. Insomnia
e. Parkinson's disease

3. St. John's wort has demonstrated efficacy in randomized controlled trials for which one of the following indications?
a. Alzheimer's disease
b. Benign prostatic hypertrophy
c. Depression
d. Insomnia
e. Parkinson's disease

4. Saw palmetto has demonstrated efficacy in randomized controlled trials for which one of the following indications?
a. Alzheimer's disease
b. Benign prostatic hypertrophy
c. Depression
d. Insomnia
e. Parkinson's disease

5. Which of the following symptoms is a side effect of ginseng?
a. Decreased libido
b. Dermopathies
c. Morning drowsiness
d. Nervousness

6. Which of the following symptoms is a side effect of kava?
a. Decreased libido
b. Dermopathies
c. Morning drowsiness
d. Nervousness

7. Which of the following symptoms is a side effect of valerian?

a. Decreased libido

b. Dermopathies

c. Morning drowsiness

d. Nervousness
8. Which of the following precautions should patients be given about garlic?

a. Do not mix with other agents that affect platelets.

b. Do not operate heavy machinery or drive after ingesting.

c. Do not take if history of hepatic or renal disease.

d. Do not take for longer than eight weeks.

9. Which of the following precautions should patients be given about echinacea?

a. Do not mix with other agents that affect platelets.

b. Do not operate heavy machinery or drive after ingesting.

c. Do not take if history of hepatic or renal disease.

d. Do not take for longer than eight weeks.

10. Which of the following precautions should patients be given about kava?

a. Do not mix with other agents that affect platelets.

b. Do not operate heavy machinery or drive after ingesting.

c. Do not take if history of hepatic or renal disease.

d. Do not take for longer than eight weeks. 
DEMOGRAPHIC

\section{INFORMATION}

(not for scoring)

1. In what type of setting do you work (leave blank if none of the responses below applies)?
a. HMO.
b. PPO
c. Indemnity insurance.
d. Pharmacy benefits management.
e. Other.

12. Did this program achieve its educational objectives?

a. Yes.

b. No.
13. How many minutes did it take you to complete this program, including the quiz (fill in on answer sheet)?

14. Did this program provide insights relevant or practical for you or your work?
a. Yes.
b. No.

15. Please rate the quality of this $\mathrm{CE}$ article.
a. Excellent.
b. Good.
c. Fair
d. Poor.

\section{INSTRUCTIONS}

This quiz affords 1 hour ( 1 CEU) of continuing pharmaceutical education in all states that recognize the American Council on Pharmaceutical Education. To receive credit, you must score at least $70 \%$ of your quiz answers correctly. To record an answer, darken the appropriate block below. Mail your completed answer sheet to: Academy of Managed Care Pharmacy, $100 \mathrm{~N}$. Pitt Street, Suite 400, Alexandria, VA 22314. Assuming a score of $70 \%$ or more, a certificate of achievement will be mailed to you within 30 days. If you fail to achieve $70 \%$ on your first try, you will be allowed only one retake. The ACPE Provider Number for this lesson is 233-000-99-004-H01. This offer of continuing education credits expires August 31, 2000.

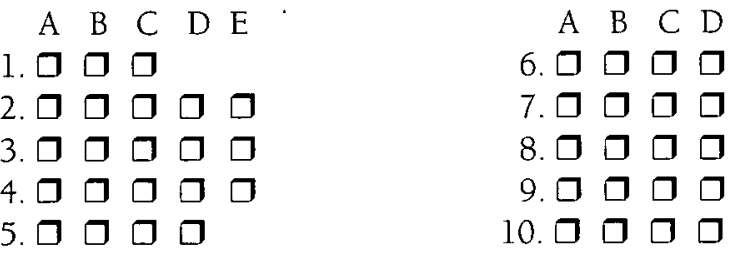

11. $\square$ A $\square$ B $\square$ C $\square \square E$
12. $\square$ Yes $\square$ No
13. Minutes $\frac{}{\text { 14. } \square \text { Yes } \square \text { No }}$
15. $\square$ A $\square$ B $\square D$

Participant Identification: Please type or print

Date

Social Security \#

For Identification Purposes Only

Name

Last

First

Middle

Work Phone \#

Company

Address

Street (with Apt. No.) or P.O. Box

City

State

Zip

State and Lic. No.

State No:

Member Type: $\square$ Active $\square$ Supporting Associate

$\square$ Student $\square$ Nonmember

Signature 